\title{
Factors affecting age at menopause among Saudi women in Riyadh, SA: a cross-sectional study
}

\author{
ABEER SALEM AL SHAHRANI ${ }^{1, A}, \mathrm{c}-\mathrm{F}$, SHAHAD FARAJ 2, A, B, c, F, ALANOOD ALHARGAN $2, \mathrm{~A}, \mathrm{~B}, \mathrm{c}, \mathrm{F}$, \\ MALAK ALJUMAID 2, A, B, c, F, ASMAA GOSTY2, A, B, c, F, MONA AL-SUGAIR 2, A, B, c, F, \\ MASHAEL ALJUWAYED 2, A, B, c, F, ASMA AL JUHAIMI', A, B, c, F
}

${ }^{1}$ Department of Clinical Sciences, College of Medicine, Princess Nourah bint Abdulrahman University, Riyadh, Saudi Arabia

${ }^{2}$ Medical Students, College of Medicine, Princess Nourah bint Abdulrahman University, Riyadh, Saudi Arabia

A - Study Design, B - Data Collection, C - Statistical Analysis, D - Data Interpretation, E - Manuscript Preparation, F - Literature Search, G - Funds Collection

Summary Background. Women experience many changes over the course of life, from menarche to pregnancy and menopause. The factors affecting natural menopause and the variation in women's menopausal age are not understood. Few studies to date have examined the mean age of menopause and factors affecting it among Saudi women.

Objectives. To determine the association between menopausal age and lifestyle and reproductive factors. To assess knowledge and preventive practices relating to menopause.

Material and methods. This cross-sectional study involved 500 Saudi women between the ages of 45 and 65 years who had no history of breast cancer or surgically induced menopause. Data were collected using a self-administered questionnaire.

Results. The study involved 500 Saudi women aged 45-65, with a mean age of 51.4. \pm 5.06 years and an average age at natural menopause of $49.5 \pm 4.9$ years. Approximately $49.4 \%$ of participants were premenopausal, $21.8 \%$ were perimenopausal, and $28.8 \%$ were post-menopausal. Analysis of lifestyle factors revealed that $26 \%$ never exercised and $56.6 \%$ were obese. Regarding the influence of obstetric factors, there were statistically significant differences between groups based on age at menarche, age at marriage, maternal age at menopause, and number of pregnancies. We also assessed knowledge and health care practices (including mammograms, pap smears, DXA, vitamin D and calcium use, and colonoscopy) and menopausal status.

Conclusions. BMI, age at menarche, maternal age at menopause, marital age and parity are associated with age at natural menopause. Knowledge about menopause did not influence common preventive measures for postmenopausal women.

Key words: factors, practice, age at natural menopause.

Al Shahrani AS, Faraj S, Alhargan A, Aljumaid M, Gosty A, Al-Sugair M, Aljuwayed M, Al Juhaimi A. Factors affecting age at menopause among Saudi women in Riyadh, SA: a cross-sectional study. Fam Med Prim Care Rev 2018; 20(1): 55-60, doi: https://doi.org/10.5114/ fmpcr.2018.73704.

\section{Background}

Women experience many changes over the course of their life, from menarche to pregnancy, before reaching the end of their reproductive years. The onset of menopause marks the end of a women's reproductive life [1]. Moreover, age at natural menopause (ANM) is considered a sentinel factor for chronic disease risk in later life. Delayed natural menopause is associated with an increased risk of breast and endometrial cancer, whereas early ANM increases the risk of osteoporosis and cardiovascular diseases [2]. Thus, determining the age at menopause is important, and studying associated factors, especially modifiable ones, is an increasingly important research topic worldwide.

ANM appears to vary between populations, and even more so among women within the same race/ethnicity. Epidemiological studies have reported an average age at onset of perimenopause of 47.5 years, with slight evidence of increasing age at menopause over time [3]. One systematic review identified the mean age at natural menopause as 48.8 years. This number differs by ethnicity/race [1]. In Saudi Arabia, one study has reported that the mean age at natural menopause is 48.98 years, with a median age of 50 years [4].
To this day, factors affecting the onset of natural menopause remain controversial. Thus, it is difficult to predict the exact age of menopause. However, some studies have shown that variation in menopausal age could be explained by genetic, environmental, socioeconomic, lifestyle and reproductive factors [5-7].

Previous studies have found that early age at menopause was associated with lower education, unemployment, being separated, divorced, or widowed [6], poor economic status [8], and smoking $[9,10]$. On the other hand, education and employment have been found to be associated with later ANM [1]. Several studies have examined the association of BMI and physical activity with natural menopause, yielding inconsistent findings. One study reported that increased BMI and certain patterns of body fat distribution were associated with delayed age at menopause [11]. Moreover, premenopausal history of episodic weight loss of more than $5 \mathrm{~kg}$ was independently associated with later ANM [12]. Women who maintain regular physical activity had a significantly later menopause [13]. However, in the renowned ALSWH study, there was no effect of physical activity on ANM [14]. Studies of diet and ANM have shown conflicting results $[15,16]$. It is hypothesized that diet may influence menopause via its effect on serum estradiol. However, large prospective studies are needed to draw such conclusions [6]. 
In addition to modifiable socioeconomic and lifestyle factors, there are some non-modifiable factors that influence ANM. It is well recognized that both age at menarche and age at menopause are influenced by genetic loci [17]. This effect was identified by genome-wide association studies among women from various populations $[7,18]$. One study conducted among Chinese women found that menarche at an age younger than 14 years was associated with earlier onset of natural menopause [8]. Several epidemiological studies have established that maternal age at menopause affects menopausal age in their daughters $[3,19]$ and has a significant effect on serum biomarkers of ovarian reserve [20].

The World Health Organization (WHO) estimates that life expectancy will increase by the year 2050 , and that there will be one billion women over the age of 60 years [21]. Thus, it is important to study knowledge and attitudes toward this important stage of women's life [22], taking in consideration the impact of culture on this experience [23].

\section{Objectives}

To our knowledge, there is a lack of studies investigating ANM and its associated factors in our population, and there is a need for further study of Saudi women's knowledge and practices regarding menopause. The aim of this study was to determine the relationship between menopausal age and certain reproductive and lifestyle factors, as well as to assesses the knowledge and practices of the selected population regarding menopause.

\section{Methodology}

Study design cross-sectional study.

Setting two district hospitals (Prince Mohammed bin AbdulAziz hospital \& King Fahad medical city) and the King Salman social centre. It was conducted over a 3-month period in 2016, in Riyadh.

Participants it involved Saudi women aged $45-65$ years attending outpatient clinics. Women with breast cancer \pm chemotherapy and those with surgically induced menopause were excluded.

Variables including: sociodemographic data, some reproductive factors such as age at menarche, age at $1^{\text {st }}$ marriage, maternal menopausal age, menstrual cycle duration and regularity, number of pregnancies and children, and the use and type of contraception methods. Lifestyle factors included exercise and diet. Participants underwent an assessment of weekly consumption of selected types of food and drinks, such as coffee, honey, fish, soy and flax-seeds. As our primary objective in this study was the assessment of factors associated with age at menopause, the portion of the study assessing knowledge and practices focused mainly on women's knowledge of menopausal symptoms, HRT use, and the commonest preventive measures employed in this age group (including sun exposure, DXA scans, mammograms, pap smears, colonoscopy, and calcium and vitamin D intake). We plan to explore these factors in a future study.

Data sources/measurement participants were asked to fill in an Arabic-language, self-administered questionnaire that was designed based on previous literature. Weight $\&$ height were measured to calculate BMI.

Bias as expected with this type of study, recall bias \& digit preference bias.

Study size we used a convenience sampling technique and calculated the sample size using a statistical software program [24], considering that we had to estimate means and proportions in our data. Thus, the minimum acceptable sample size was 377 individuals [25].

Quantitative variables including: age, weight, height, BMI, age at menarche, age at $1^{\text {st }}$ marriage, maternal menopausal age, number of pregnancies, number of children, length of cycle, duration of ceased period.

Statistical methods statistical analysis was performed using SPSS statistical software (release 24 , SPSS Inc., Chicago, US). We managed missing data using the mean of series responses. However, we have little missing data because data were collected by interview, making it unlikely to have missing responses. Assessment of the reliability of the tested items yielded a Cronbach's Alpha of 0.66 . The completed questionnaire was checked and pretested for clarity and suitability among 50 individuals. Given that our sample size was relatively acceptable, we used the Kolmogorov-Smirnov test for continuous data such as age and other quantitative variables to evaluate data distribution. We presented data as frequencies and proportions for categorical data such as education level, marital status, etc., and mean and standard deviation (SD) for continuous data such as age at menarche, age at marriage, number of pregnancies, and number of children. Data on age at menarche, age at marriage, number of pregnancies, and number of children were found to be normally distributed. Thus, we used ANOVA (F-test) to compare means by menopausal status. We used the chi-square test to assess associations between categorical variables and menopausal status. A $p$-value $\leq 0.05$ was considered significant.

Bioethical considerations: the university's IRB board has approved this study. It involves patients who agreed to participate. Data are anonymous and will be used for research purposes. There is no conflict of interest to be declared. This study is based on a research project for medical students and their supervisor as part of their curriculum. The study has not received any funds.

\section{Results}

\section{Descriptive Data}

\section{Characteristics of the study population}

The study involved 500 Saudi women aged 45-65 with a mean age of $51.4 \pm 5$. Two hundred and forty-seven women (49.4\%) were premenopausal, 109 (21.8\%) were peri-menopausal, and $144(28.8 \%)$ were postmenopausal (Figure 1). The mean age of menopause was 49.5 with $S D=4.9$. The majority of women (85.2\%) were married; $42 \%$ had received university education, and $60 \%$ were unemployed. Approximately $53 \%$ were generally healthy, with $97.6 \%$ non-smokers. We measured participants' BMI and found that $56.6 \%$ were obese and $30.6 \%$ were overweight (Table 1).

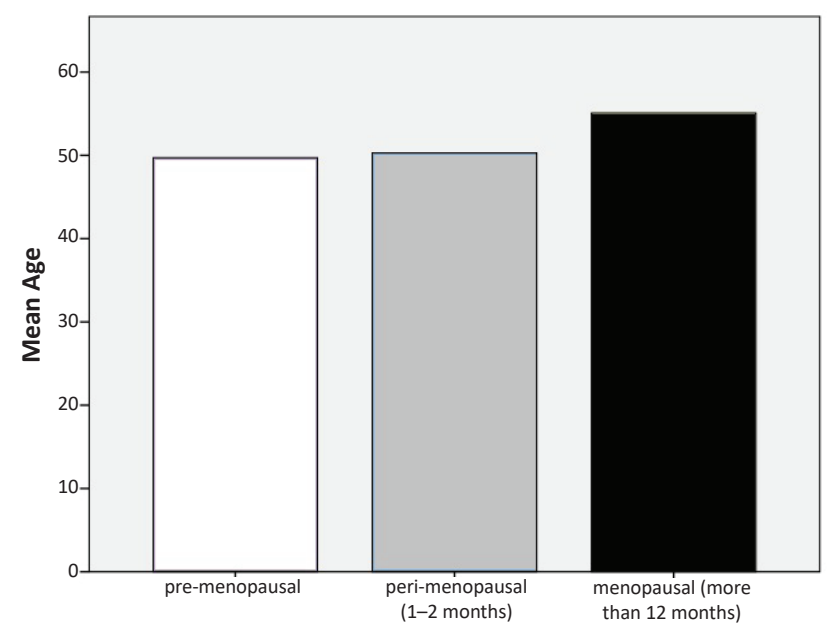

Menopausal status

Figure 1. Menopausal status 


\begin{tabular}{|c|c|c|c|}
\hline & & Frequency & Valid \% \\
\hline \multirow[t]{3}{*}{ Age } & 45 to 49 & 186 & 37.2 \\
\hline & 50 to 55 & 167 & 33.4 \\
\hline & $>55$ & 147 & 29.4 \\
\hline \multirow[t]{5}{*}{ Education } & primary & 49 & 9.8 \\
\hline & elementary & 58 & 11.6 \\
\hline & high school & 141 & 28.2 \\
\hline & college \& above & 211 & 42.2 \\
\hline & uneducated & 41 & 8.2 \\
\hline \multirow[t]{4}{*}{ Marital status } & married & 426 & 85.2 \\
\hline & single & 6 & 1.2 \\
\hline & widowed & 47 & 9.4 \\
\hline & divorced & 21 & 4.2 \\
\hline \multirow[t]{3}{*}{ Occupation } & unemployed & 298 & 59.6 \\
\hline & non-health worker & 180 & 36 \\
\hline & health worker & 22 & 4.4 \\
\hline \multirow{7}{*}{$\begin{array}{l}\text { Chronic } \\
\text { diseases }\end{array}$} & absent & 262 & 52.4 \\
\hline & present & 238 & 47.6 \\
\hline & HTN & 81 & 16.2 \\
\hline & DM & 115 & 23 \\
\hline & dyslipidemia & 81 & 16.2 \\
\hline & CVS diseases & 14 & 2.8 \\
\hline & other* & 99 & 19.8 \\
\hline \multirow{3}{*}{$\begin{array}{l}\text { Smoking } \\
\text { status }\end{array}$} & non-smoker & 489 & 97.8 \\
\hline & ex-smoker & 5 & 1.0 \\
\hline & current smoker & 6 & 1.2 \\
\hline \multirow[t]{4}{*}{ BMI } & normal & 64 & 12.8 \\
\hline & overweight & 153 & 30.6 \\
\hline & obese & 283 & 56.6 \\
\hline & Total & 500 & 100 \\
\hline
\end{tabular}

* - statistical significance.

\section{Main results}

\section{Factors affecting menopausal age}

With regard to lifestyle factors we found that $61 \%$ were practicing exercise once to three times per week. Compared with women who did not exercise, there was no significant difference in menopausal age. BMI showed a statistically significant association with menopausal status $(p=0.007)$.

Regarding the effect of diet (Table 2), we found that the majority of the study population consumed fish and Arabic coffee (64\% and $54 \%$ respectively), but this had no association with menopausal status. The majority of participants reported that they never consume soy beans or flax seeds $(85 \%$ and $90 \%$ respectively). Interestingly, honey consumption showed a statistically significant association, especially for those using one spoon of honey more than 3 times a week.

Regarding reproductive factors, we found that multiple factors were associated with menopause, including maternal age at menopause $(p=0.001)$, age at menarche $(p=0.023)$, age at marriage $(p=0.013)$, and number of pregnancies $(p=0.026)$. However, there was no statistically significant association with cycle length or contraception use (Table 3).

\begin{tabular}{|c|c|c|c|c|c|}
\hline & & Frequency & Valid \% & $\begin{array}{l}\text { ANOVA } \\
\mathrm{F}\end{array}$ & Sig. \\
\hline \multirow[t]{4}{*}{ Exercise } & never & 130 & 26.0 & \multirow{4}{*}{0.561} & \multirow{4}{*}{0.571} \\
\hline & $1-3$ & 308 & 61.6 & & \\
\hline & $4-6$ & 40 & 8.0 & & \\
\hline & daily & 22 & 4.4 & & \\
\hline \multirow[t]{4}{*}{ Fish } & never & 164 & 32.8 & \multirow{4}{*}{1.976} & \multirow{4}{*}{0.140} \\
\hline & $\begin{array}{l}\text { less than } \\
3 \text { times }\end{array}$ & 320 & 64 & & \\
\hline & 3 times & 9 & 1.8 & & \\
\hline & $\begin{array}{l}\text { more than } \\
3 \text { times }\end{array}$ & 7 & 1.4 & & \\
\hline \multirow[t]{5}{*}{ Soya } & never & 423 & 84.6 & \multirow{5}{*}{1.264} & \multirow{5}{*}{0.283} \\
\hline & $\begin{array}{l}\text { less than } \\
3 \text { times }\end{array}$ & 67 & 13.4 & & \\
\hline & 3 times & 8 & 1.6 & & \\
\hline & $\begin{array}{l}\text { more than } \\
3 \text { times } \\
\end{array}$ & 1 & 0.2 & & \\
\hline & daily & 1 & 0.2 & & \\
\hline \multirow{5}{*}{$\begin{array}{l}\text { Flax } \\
\text { seeds }\end{array}$} & never & 452 & 90.4 & \multirow{5}{*}{0.087} & \multirow{5}{*}{0.916} \\
\hline & $\begin{array}{l}\text { less than } \\
3 \text { times }\end{array}$ & 32 & 6.4 & & \\
\hline & 3 times & 8 & 1.6 & & \\
\hline & $\begin{array}{l}\text { more than } \\
3 \text { times }\end{array}$ & 4 & 0.8 & & \\
\hline & daily & 4 & 0.8 & & \\
\hline \multirow{5}{*}{$\begin{array}{l}\text { Arabic } \\
\text { coffee }\end{array}$} & never & 48 & 9.6 & \multirow{5}{*}{0.531} & \multirow{5}{*}{0.589} \\
\hline & $\begin{array}{l}\text { less than } \\
3 \text { times }\end{array}$ & 73 & 14.6 & & \\
\hline & 3 times & 22 & 4.4 & & \\
\hline & $\begin{array}{l}\text { more than } \\
3 \text { times }\end{array}$ & 269 & 53.8 & & \\
\hline & daily & 88 & 17.6 & & \\
\hline \multirow[t]{6}{*}{ Honey } & never & 199 & 39.8 & \multirow{5}{*}{3.438} & \multirow{5}{*}{$0.033^{*}$} \\
\hline & $\begin{array}{l}\text { less than } \\
3 \text { times }\end{array}$ & 177 & 35.4 & & \\
\hline & 3 times & 34 & 6.8 & & \\
\hline & $\begin{array}{l}\text { more than } \\
3 \text { times }\end{array}$ & 75 & 15.0 & & \\
\hline & daily & 15 & 3.0 & & \\
\hline & Total & 500 & 100 & & \\
\hline
\end{tabular}

* - statistical significance.

Table 3. Reproductive factors among pre/peri/post-menopausal women

\begin{tabular}{|c|c|c|c|c|c|}
\hline & & $\begin{array}{l}\text { Fre- } \\
\text { quency }\end{array}$ & Valid \% & $\begin{array}{l}\text { ANOVA } \\
\mathrm{F}\end{array}$ & Sig. \\
\hline \multirow{5}{*}{$\begin{array}{l}\text { Maternal } \\
\text { age at } \\
\text { meno- } \\
\text { pause }\end{array}$} & do not know & 123 & 24.6 & \multirow{5}{*}{9.535} & \multirow{5}{*}{$0.001^{*}$} \\
\hline & $40-44$ & 25 & 5.0 & & \\
\hline & $45-49$ & 106 & 21.2 & & \\
\hline & $50-54$ & 192 & 38.4 & & \\
\hline & $\begin{array}{l}\text { more than } \\
55\end{array}$ & 54 & 10.8 & & \\
\hline \multirow[t]{4}{*}{$\begin{array}{l}\text { Duration } \\
\text { of period }\end{array}$} & $\begin{array}{l}\text { less than } 3 \\
\text { days }\end{array}$ & 7 & 1.4 & \multirow[t]{4}{*}{0.499} & \multirow[t]{4}{*}{0.607} \\
\hline & 4-5 days & 88 & 17.6 & & \\
\hline & $6-7$ days & 315 & 63.0 & & \\
\hline & $\begin{array}{l}\text { more than } \\
7 \text { days }\end{array}$ & 90 & 18.0 & & \\
\hline
\end{tabular}




\begin{tabular}{|c|c|c|c|c|c|}
\hline & & \begin{tabular}{|l} 
Fre- \\
quency
\end{tabular} & Valid \% & \begin{tabular}{|l} 
ANOV \\
$\mathrm{F}$ \\
\end{tabular} & Sig. \\
\hline \multirow{6}{*}{$\begin{array}{l}\text { Contra- } \\
\text { ception } \\
\text { use }\end{array}$} & no & 91 & 18.2 & \multirow[t]{2}{*}{0.127} & \multirow[t]{2}{*}{0.881} \\
\hline & yes* & 409 & 81.8 & & \\
\hline & OCPs & 352 & 70.4 & & \\
\hline & IUCD & 174 & 34.8 & & \\
\hline & $\begin{array}{l}\text { hormonal } \\
\text { patches }\end{array}$ & 10 & 2 & & \\
\hline & vaginal ring & 7 & 1.4 & & \\
\hline $\begin{array}{l}\text { Age at } \\
\text { menarche }\end{array}$ & $\begin{array}{l}\text { mean } \pm \\
\text { Std. D }\end{array}$ & \multicolumn{2}{|c|}{$(12.8) \pm 1.65$} & 3.790 & $0.023^{*}$ \\
\hline $\begin{array}{l}\text { Age at } \\
\text { marriage }\end{array}$ & $\begin{array}{l}\text { mean } \pm \\
\text { Std. D }\end{array}$ & \multicolumn{2}{|l|}{$(20) \pm 4.5$} & 4.348 & $0.013^{*}$ \\
\hline $\begin{array}{l}\text { Number } \\
\text { of preg- } \\
\text { nancies }\end{array}$ & $\begin{array}{l}\text { mean } \pm \\
\text { Std. D }\end{array}$ & \multicolumn{2}{|l|}{$(7) \pm 3.06$} & 3.665 & $0.026^{*}$ \\
\hline $\begin{array}{l}\text { Number } \\
\text { of chil- } \\
\text { dren }\end{array}$ & $\begin{array}{l}\text { mean } \pm \\
\text { Std. D }\end{array}$ & \multicolumn{2}{|c|}{$(5.6) \pm 2.5$} & 0.572 & 0.565 \\
\hline
\end{tabular}

* - statistical significance.

\section{Knowledge and practices regarding menopause}

In this study, menopause knowledge refers to the degree of understanding of menopausal symptoms and use of hormonal therapy, and practices refer to the use of common preventive health care practices applicable to this age group. With regard to knowledge of menopausal symptoms, $50 \%$ of pre-menopausal women were not aware of psychosomatic, vasomotor or urogenital symptoms, compared to $53 \%$ of peri-menopausal women and $46.5 \%$ of post-menopausal women. The majority of participants were also unaware of HRT use for menopause. Lack of awareness was more common among peri-menopausal women, but there was no statistically significant difference between the three groups.

Regarding preventive practices for osteoporosis, most participants had not undergone a DXA scan, including one-third of postmenopausal women. This difference was statistically significant $(p=0.005)$. Moreover, $75 \%$ of the study population had no sun exposure on a regular basis. Lastly, calcium \& vitamin D intake was common, especially in the peri-menopausal group (52\%). Regarding common cancer prevention practices, only one-third of the study population had undergone a mammogram within 1 year, and fewer than $25 \%$ had undergone cervical cancer screening. Colonoscopy was the least commonly completed preventive measure, reported by only $6 \%$ of participants. There was no statistically significant difference with regard to menopausal status for any of these preventive measures. The prevalence of HRT use was $21 \%$, and half of the women using HRT were post-menopausal.

\section{Discussion}

\section{Key results and their interpretations}

Based on the general characteristics of the study population the mean age at menopause in our study was 49.5 years. To the best of our knowledge there have been few publications regarding ANM distribution in Saudi Arabia, with previous studies reporting a mean ANM of 48 years $[4,26]$. This finding is similar to the findings of other previous studies $[1,27]$. In our study, $47 \%$ of participants suffered from one or more chronic diseases, with a higher prevalence among post-menopausal women. There is growing evidence that age at natural menopause is an independent risk factor for a number of chronic diseases [28].
One systematic review has shown that early age at menopause is associated with CVS disease. However, the effects of time since menopause showed inconsistent results [29]. This finding has important clinical implications for planning \& implementing screening and preventive measures in our community.

Although smoking is the most established and consistently observed risk factor for early age at menopause $[9,10]$, interestingly, smoking was not common in our study population, with only $1.2 \%$ current smokers. However, we found a significant association with $\mathrm{BMI}$, which is consistent with the findings of other epidemiological studies [6, 13]. Moreover, BMI has been used to predict age at menopause, with higher BMI being associated with later ANM [30]. Interestingly, most participants in the study were either obese or overweight. This finding supports previous studies that showed an increasing prevalence of obesity among the Saudi population [31], with females being more significantly obese than males [32, 33]. This might be explained by hormonal changes that occur during the peri-menopausal period and influence increases in abdominal fat [34]. Although we expected that culture influences dietary habits among the Saudi population, the effect of diet on menopausal age was not conclusive. This was probably due to the selection of a few dietary elements and study design. Few studies to date have addressed the association between diet and age at menopause. A Japanese diet that contains soy is associated with late ANM [6], whereas a high intake of polyunsaturated fats accelerates ANM [35]. One of the interesting findings in this study is that honey consumption might be associated with age at menopause. However, with our study design it is difficult to prove this association and its clinical significance. A few studies have addressed the effect of honey on menopausal symptoms $[36,37]$. Further exploration of the effects of different types of honey and preparations is needed.

Prior studies, especially those that hypothesized the influence of ovulation or follicle attrition, have shown somewhat controversial results with respect to the timing of natural menopause. Our results are consistent with previous reports with regard to the influence of age at menarche $[8,38]$, maternal age at menopause [19], age at marriage [39], and parity [40, 41] on menopausal age. Moreover, other analyses have reported that parity was not a prediction factor per se, but that age at last delivery was directly associated with menopausal age [42]. However, this study did not demonstrate any association with other reproductive factors, such as menstrual cycle length and contraception use.

Educated women demonstrated better knowledge about menopause than non-educated women. Health care workers also had better knowledge of menopausal symptoms and HRT than non-health care workers and unemployed women. Approximately $49.3 \%$ of Saudi women have good knowledge of how many times they should be screened for breast cancer with a mammogram, and $52.3 \%$ know how many times they should be screened for cervical cancer with a pap smear. However, this knowledge did not extend to the frequency of screening and preventive practices for menopause. In contrast, other studies have shown a positive correlation between attitude and management $[43,44]$. This might be explained by multiple reasons.

To minimize the effect of recall bias, we asked about frequency of screening and preventive practices within one year only. Further analysis is needed to adjust for age. Our results regarding knowledge about HRT and its use to alleviate menopausal symptoms are consistent with those of previous studies [45-47]. In addition to women's lack of knowledge about HRT use, it seems that underuse of hormonal therapy could be due to physicians' hesitance to prescribe these medications despite current recommendations that favour the use of HRT for patients younger than 60 with no contraindications [48].

\section{Generalizability}

To our knowledge, few local studies have assessed factors affecting age at natural menopause in the Saudi community. 
Moreover, there have been few studies conducted to evaluate knowledge, attitudes and practices regarding menopausal symptoms [49,50], as well as quality of life [26]. This study adds to the growing body of evidence that onset of menopause is determined by an interaction of multiple factors that are not merely inheritable. Therefore, the reported data can be explored in more depth to improve women's experience with menopausal care.

\section{Limitations of the study}

One major limitation is the study design. The inconsistent results may be due to the retrospective or cross-sectional nature of the data. Other limitations common with this type of study include recall bias and digit preference bias.

\section{Conclusions}

Previous studies have described associations of age at menopause with socio-demographic and reproductive factors.
The results of these studies have been conflicting, except for the finding that menopause occurs earlier in smokers than in nonsmokers. The current study supports previous findings of a significant association with $\mathrm{BMI}$, age of menarche, maternal age at menopause, marital age, and number of pregnancies, which might determine age at menopause among Saudi women. However, the other inconclusive results may be due to the retrospective or cross-sectional nature of the data. Thus a large, multi-centre prospective study could better identify the type and nature of these associations. In addition, the high prevalence of overweight \& obesity in the study population points to a considerable risk to public health and merits greater attention at the community level. Family medicine is the speciality that addresses such problems, and has its own unique role in health promotion and prevention. It is unclear whether patients' knowledge about menopause and its associated health risks may affect the utilization of preventive measures. More efforts should be made to enforce the implementation of preventive practices for common health problems that occur during the postmenopausal period.

Source of funding: This work was funded by the authors' own resources.

Conflict of interest: The authors declare no conflict of interests.

\section{References}

1. Schoenaker DA, Jackson CA, Rowlands JV, et al. Socioeconomic position, lifestyle factors and age at natural menopause: a systematic review and meta-analyses of studies across six continents. Int J Epidemiol 2014; 43(5): 1542-1562.

2. Ahuja M. Age of menopause and determinants of menopause age: a PAN India survey by IMS. J Midlife Health 2016; 7(3): 126-131.

3. Gold EB. The timing of the age at which natural menopause occurs. Obstet Gynecol Clin North Am 2011; 38(3): 425-440.

4. Greer W, Sandridge AL, Chehabeddine RS. The frequency distribution of age at natural menopause among Saudi Arabian women. Maturitas 2003; 46(4): 263-272.

5. Stepaniak U, Szafraniec K, Kubinova R, et al. Age at natural menopause in three Central and Eastern European urban populations: the HAPIEE study. Maturitas 2013; 75(1): 87-93.

6. Sapre S, Thakur R. Lifestyle and dietary factors determine age at natural menopause. J Midlife Health 2014; 5(1): 3-5.

7. Murray A, Bennett CE, Perry JR, et al. Common genetic variants are significant risk factors for early menopause: results from the Breakthrough Generations Study. Hum Mol Genet 2011; 20(1): 186-192.

8. Li L, Wu J, Pu D, et al. Factors associated with the age of natural menopause and menopausal symptoms in Chinese women. Maturitas 2012; 73(4): 354-360.

9. Sun L, Tan L, Yang F, et al. Meta-analysis suggests that smoking is associated with an increased risk of early natural menopause. Menopause 2012; 19(2): 126-132.

10. Hayatbakhsh MR, Clavarino A, Williams GM, et al. Cigarette smoking and age of menopause: a large prospective study. Maturitas 2012; 72(4): 346-352.

11. Reynolds RF, Obermeyer CM. Age at natural menopause in Spain and the United States: results from the DAMES project. Am J Hum Biol 2005; 17(3): 331-340.

12. Aydin ZD. Determinants of age at natural menopause in the Isparta Menopause and Health Study: premenopausal body mass index gain rate and episodic weight loss. Menopause 2010; 17(3): 494-505.

13. Morris $\mathrm{DH}$, Jones $\mathrm{ME}$, Schoemaker MJ, et al. Body mass index, exercise, and other lifestyle factors in relation to age at natural menopause: analyses from the breakthrough generations study. Am J Epidemiol 2012; 175(10): 998-1005.

14. Dobson AJ, Hockey R, Brown WJ, et al. Cohort profile update: Australian longitudinal study on women's health. Int J Epidemiol 2015; 44(5): 1547, 1547a-1547f, doi: 10.1093/ije/dyv110.

15. Nagel G, Altenburg HP, Nieters A, et al. Reproductive and dietary determinants of the age at menopause in EPIC-Heidelberg. Maturitas 2005; 52(3-4): 337-347.

16. Tsuji M, Tamai Y, Wada K, et al. Associations of intakes of fat, dietary fiber, soy isoflavones, and alcohol with levels of sex hormones and prolactin in premenopausal Japanese women. Cancer Causes Control 2012; 23(5): 683-689.

17. Voorhuis M, Onland-Moret NC, Van der Schouw YT, et al. Human studies on genetics of the age at natural menopause: a systematic review. Hum Reprod Update 2010; 16(4): 364-377.

18. Shi J, Zhang B, Choi JY, et al. Age at menarche and age at natural menopause in East Asian women: a genome-wide association study. AGE 2016; 38(5): 513-523.

19. Morris DH, Jones ME, Schoemaker MJ, et al. Familial concordance for age at natural menopause: results from the Breakthrough Generations Study. Menopause 2011; 18(9): 956-961.

20. Bentzen JG, Forman JL, Larsen EC, et al. Maternal menopause as a predictor of anti-Mullerian hormone level and antral follicle count in daughters during reproductive age. Hum Reprod 2013; 28(1): 247-255.

21. World Health Organization. Women, Ageing and Health. A Framework for Action. Focus on Gender. 2007. Available from URL: http:// www.who.int/ageing/publications/Women-ageing-health-lowres.pdf.

22. Hoga L, Rodolpho J, Gonçalves B, et al. Women's experiences of menopause: a systematic review protocol of qualitative evidence. JBI Database System Rev Implement Rep 2015; 13(8): 250-337, doi: 10.11124/jbisrir-2015-1948.

23. Jones EK, Jurgenson JR, Katzenellenbogen JM, et al. Menopause and the influence of culture: another gap for Indigenous Australian women? BMC Women's Health 2012; 12: 1-10, doi: 10.1186/1472-6874-12-43.

24. Raosoft. Sample size calculator. Available from URL: http://www.raosoft.com/samplesize.html. 
25. Omair A. Sample size estimation and sampling techniques for selecting a representative sample. JHS 2014; 2(4): 142-147.

26. AlDughaither A, AlMutairy H, AlAteeq M. Menopausal symptoms and quality of life among Saudi women visiting primary care clinics in Riyadh, Saudi Arabia. Int J Womens Health 2015; 29(7): 645-653.

27. Palacios S, Henderson VW, Siseles N, et al. Age of menopause and impact of climacteric symptoms by geographical region. Climacteric 2010; 13(5): 419-428.

28. Lee JS, Hayashi K, Mishra G, et al. Independent association between age at natural menopause and hypercholesterolemia, hypertension, and diabetes mellitus: Japan nurses' health study. Atheroscler Thromb 2013; 20(2): 161-169.

29. Muka T, Oliver-Williams C, Kunutsor S, et al. Association of age at onset of menopause and time since onset of menopause with cardiovascular outcomes, intermediate vascular traits, and all-cause mortality: a systematic review and meta-analysis. JAMA Cardiol 2016; 1(7): 767-776.

30. La Marca A, Sighinolfi G, Papaleo E, et al. Prediction of age at menopause from assessment of ovarian reserve may be improved by using body mass index and smoking status. PLOS ONE 2013; 8(3): e57005, doi: 10.1371/journal.pone.0057005.

31. El-Hazmi MAF, Warsy AS. Prevalence of obesity in the Saudi population. Ann Saudi Med 1997; 17(3): 302-306.

32. Al-Shammari SA, Khoja TA, al-Maatouq MA, et al. High prevalence of clinical obesity among Saudi females: a prospective, cross-sectional study in the Riyadh region. J Trop Med Hyg 1994; 97(3): 183-188.

33. Al-Nozha MM, Al-Mazrou YY, Al-Maatouq MA, et al. Obesity in Saudi Arabia. Saudi Med J 2005; 26(5): 824-829.

34. Davis SR, Castelo-Branco C, Chedraui P, et al. Understanding weight gain at menopause. Climacteric 2012; 15(5): 419-429.

35. Nagata C, Wada K, Nakamura K, et al. Associations of physical activity and diet with the onset of menopause in Japanese women. Menopause 2012; 19(1): 75-81.

36. Zaid SS, Sulaiman SA, Sirajudeen KN, et al. The effects of Tualang honey on female reproductive organs, tibia bone and hormonal profile in ovariectomised rats - animal model for menopause. MC Complement Altern Med 2010; 10: 82, doi: 10.1186/1472-6882-10-82.

37. Othman Z, Shafin N, Zakaria R, et al. Improvement in immediate memory after 16 weeks of tualang honey (Agro Mas) supplement in healthy postmenopausal women. Menopause 2011; 18(11): 1219-1224.

38. Farahmand M, Tehrani FR, Pourrajabi L, et al. Factors associated with menopausal age in Iranian women: Tehran Lipid and Glucose Study. J Obstet Gynaecol Res 2013; 39(4): 836-841.

39. Golshiri P, Akbari M, Abdollahzadeh MR. Age at natural menopause and related factors in Isfahan, Iran. J Menopausal Med 2016; 22(2): 87-93.

40. Delavar MA, Hajiahmadi M, Factors Affecting the age in normal menopause and frequency of menopausal symptoms in Northern Iran. Iranian Red Crescent Med J 2011; 13(3): 192-198.

41. Yasui T, Hayashi K, Mizunuma H, et al. Factors associated with premature ovarian failure, early menopause and earlier onset of menopause in Japanese women. Maturitas 2012; 72(3): 249-255.

42. Shin YJ, Song JY, Kim MJ, et al. Relationship between age at last delivery and age at menopause: the Korea National Health and Nutrition Examination Survey. Obstet Gynecol Sci 2017; 60(4): 362-368.

43. Kwak EK, Park HS, Kang NM. Menopause knowledge, attitude, symptom and management among midlife employed women. $J$ Menopausal Med 2014; 20(3): 118-125.

44. Noroozi E, Dolatabadi N, Eslami A, et al. Knowledge and attitude toward menopause phenomenon among women aged 40-45 years. J Educ Health Promot 2013; 30(2): 25, doi: 10.4103/2277-9531.112701.

45. Hamid S, Al-Ghufli FR, Raeesi HA, et al. Women's knowledge, attitude and practice towards menopause and hormone replacement therapy: a facility based study in Al-Ain, United Arab Emirates. J Ayub Med Coll Abbottabad 2014; 26(4): 448-454.

46. Pathak V, Ahirwar N, Ghate S. Study to assess knowledge, attitude among menopausal women attending outdoor in tertiary care center. IJRCOG 2017; 6(5): 1848-1853.

47. Tao $\mathrm{M}$, Teng $\mathrm{Y}$, Shao $\mathrm{H}$, et al. Knowledge, perceptions and information about hormone therapy $(\mathrm{HT})$ among menopausal women: a systematic review and meta-synthesis. PLoS ONE 2011; 6(9): e24661, doi: https://doi.org/10.1371/journal.pone.0024661.

48. The 2017 hormone therapy position statement of the North American Menopause Society. Menopause 2017; 24(7): 728-753.

49. Al-Olayet AM, Al-Qahtani IF, Al-Esaa DI, et al. Severity of menopausal symptoms, and knowledge, attitude and practices towards menopause among Saudi women. Scientific Research and Essays 2010; 5(24): 4077-4079.

50. Alquaiz JM, Siddiqui AR, Tayel SA, et al. Determinants of severity of menopausal symptoms among Saudi women in Riyadh city. Climacteric 2014; 17(1): 71-78.

Tables: 3

Figures: 1

References: 50

Received: 26.09 .2017

Reviewed: 07.10.2017

Accepted: 15.01.2017

Address for correspondence:

Abeer S. Al Shahrani, MD

College of Medicine Princess Nourah bint Abdulrahman

University Riyadh

P.O. Box 11483

Saudi Arabia

Tel.: +966 118238991

E-mail: drabeer_fm@yahoo.com, asalshahran@pnu.edu.sa 